\title{
Impact of Sucrose Addition on the Physiochemical Properties and Volatile Compounds of "Shuangyou" Red Wines
}

\author{
Huan Liu, ${ }^{1,2,3}$ Mei-Ling Bao, ${ }^{1}$ Hong-Ling Chen, ${ }^{1}$ and Qiao $\mathrm{Li}^{1}$ \\ ${ }^{1}$ Department of Pharmaceutics and Food Science, Tonghua Normal University, Tonghua 134002, China \\ ${ }^{2}$ College of Life Sciences, Jilin University, Changchun 130012, China \\ ${ }^{3}$ Changbai Mountain Edible Plant Resources Research and Development Engineering Center, Tonghua Normal University, \\ Tonghua 134002, China \\ Correspondence should be addressed to Huan Liu; liuhuan800331@163.com
}

Received 26 February 2017; Revised 22 April 2017; Accepted 4 May 2017; Published 25 May 2017

Academic Editor: Xiuxiu Sun

Copyright (C) 2017 Huan Liu et al. This is an open access article distributed under the Creative Commons Attribution License, which permits unrestricted use, distribution, and reproduction in any medium, provided the original work is properly cited.

\begin{abstract}
"Shuangyou," a Vitis amurensis Rupr. variety, is widely cultivated in northeastern and western China. Its berries have high acidity and low sugar content. In this study, different proportions of sucrose were added to the must samples during fermentation to investigate the effect of sugar on the physicochemical properties and volatile compounds of "Shuangyou" wines. The addition of sucrose significantly improved yeast growth and alcohol production, altered the color qualities, and slightly decreased titratable acidity during fermentation. The highest tested proportion of added sucrose resulted in the highest maximum yeast counts and final ethanol concentrations. Moreover, 37 volatile compounds (esters, alcohols, fatty acids, ketones, and aldehydes) were identified and quantified by solid-phase microextraction with gas chromatography-mass spectrometry. The concentrations of these compounds were correlated with the addition of sucrose. Furthermore, the addition of $100 \mathrm{~g} / \mathrm{L}$ sucrose was sufficient for improving the concentrations of the aromatic compounds. The increase in ester, alcohol, and fatty acid concentration led to a positive OAVs impact (odor activity value $>1$ ) at the end of fermentation.
\end{abstract}

\section{Introduction}

The "Shuangyou" grape, a Vitis amurensis Rupr. grape cultivar, is a member of the Vitaceae family from China [1]. During the mid-1980s, it was successfully selected from the wild $V$. amurensis resources [2]. Nowadays, it is widely cultivated both in western and in northeastern China and is considered the most important cultivar of $V$. amurensis.

V. amurensis grape berries have high acidity $(15-30 \mathrm{~g} / \mathrm{L})$, a high tannin and polyphenol content, and a low sugar content $(80-170 \mathrm{~g} / \mathrm{L})$. They are also rich in nutrients (minerals, carotene, vitamins, etc.) $[3,4]$ that give these grapes a unique fruit fragrance and distinctive taste. Thus, $V$. amurensis grapes have become a good source of grape juice and high-quality red wine. Compared to $V$. vinifera wines, $V$. amurensis wines have a brighter ruby red color, more fragrant aroma, and a mellower and more full-bodied taste. However, this wine is also rich in bioactive substances that often impart high acidity, a very sour taste, and low alcohol content, making it less popular [5]. In order to ferment a high-quality dry red wine, producers try to reduce the acidity and enhance the sugar content in the grapes and wines by a number of methods such as delayed picking time, lactic fermentation, low-temperature treatment, dry treatment, and the addition of sucrose during the fermentation process [6-8]. Although these strategies improve deacidification and alcohol fermentation, they also excessively heighten the pungent taste, dilute the overall flavor of the wine, and lighten the fruit aroma in the final product.

During winemaking, sucrose is added to the must to increase the alcohol content and decrease acidity. In this process, sucrose is hydrolyzed into a reduced sugar that is then assimilated by yeast into ethanol and carbon dioxide [9]; the addition of each $18-20 \mathrm{~g} / \mathrm{L}$ of sugar into the grape must is predicted to enhance the final concentration of alcohol by $1 \%(\mathrm{v} / \mathrm{v})$ after fermentation [10]. Some studies have 
TABLE 1: Physicochemical characteristics of the initial musts (day 0) and wines added with sucrose and controls (day 18).

\begin{tabular}{lccccc}
\hline & Initial musts (day 0) & \multicolumn{3}{c}{ Wines (day 18) } \\
& Controls (no sucrose added) & $20 \mathrm{~g} / \mathrm{L}$ sucrose & $60 \mathrm{~g} / \mathrm{L}$ sucrose & $100 \mathrm{~g} / \mathrm{L}$ sucrose \\
\hline Yeast count $\left(\times 10^{6} \mathrm{CFU} / \mathrm{mL}\right)$ & $0.56^{\mathrm{a}} \pm 0.01$ & $0.31^{\mathrm{a}} \pm 0.11$ & $3.62^{\mathrm{b}} \pm 0.70$ & $8.31^{\mathrm{c}} \pm 1.25$ & $12.30^{\mathrm{d}} \pm 1.31$ \\
Total sugar content $(\mathrm{g} / \mathrm{L})$ & $87.75^{\mathrm{b}} \pm 2.06$ & $0.18^{\mathrm{a}} \pm 0.02$ & $0.43^{\mathrm{a}} \pm 0.05$ & $1.21^{\mathrm{a}} \pm 0.34$ & $3.00^{\mathrm{a}} \pm 0.31$ \\
Titratable acidity $(\mathrm{g} / \mathrm{L})$ & $14.95^{\mathrm{a}} \pm 0.04$ & $13.08^{\mathrm{a}} \pm 0.02$ & $13.02^{\mathrm{a}} \pm 0.07$ & $13.47^{\mathrm{a}} \pm 0.16$ & $13.70^{\mathrm{a}} \pm 0.12$ \\
Ethanol content $(\% \mathrm{v} / \mathrm{v})$ & Trace $^{*}$ & $4.90^{\mathrm{a}} \pm 0.22$ & $6.31^{\mathrm{b}} \pm 0.32$ & $8.68^{\mathrm{c}} \pm 0.38$ & $10.27^{\mathrm{d}} \pm 0.26$ \\
$L^{*}$ (lightness) & $79.13^{\mathrm{b}} \pm 3.12$ & $72.93^{\mathrm{a}} \pm 0.91$ & $73.05^{\mathrm{a}} \pm 0.53$ & $69.77^{\mathrm{a}} \pm 0.33$ & $71.22^{\mathrm{a}} \pm 0.56$ \\
$a^{*}$ (red/green) & $28.76^{\mathrm{a}} \pm 1.76$ & $35.31^{\mathrm{b}} \pm 0.68$ & $34.88^{\mathrm{b}} \pm 0.33$ & $37.68^{\mathrm{b}} \pm 0.53$ & $36.42^{\mathrm{b}} \pm 0.69$ \\
$b^{*}$ (yellow/blue) & $4.37^{\mathrm{a}} \pm 0.18$ & $4.39^{\mathrm{a}} \pm 0.15$ & $4.69^{\mathrm{a}} \pm 0.08$ & $7.17^{\mathrm{b}} \pm 0.18$ & $7.44^{\mathrm{b}} \pm 0.12$ \\
\hline
\end{tabular}

${ }^{* *}$ Values $=$ mean value \pm standard deviation $(\mathrm{SD}){ }^{* *}$ Different superscript letters in the row indicate that the differences are significant (LSD test, $\left.P<0.05\right)$.

** Trace indicates that the concentration of the compound is below the detectable level.

suggested that sugar-rich environments play an important role in yeast cell growth during wine fermentation [11, 12]. Thus, high sugar concentrations in grape musts may cause increased yeast counts and alcohol contents [13]. However, the addition of sucrose may also excessively heighten the pungent taste that destroys the other positive qualities of the wine. Furthermore, the addition of sucrose was found to alter the aroma of the final wine product. Most volatile compounds are yeast secondary metabolites whose formation in wine mainly depends on the types of alcohols and acids afforded by sugar assimilation during alcoholic fermentation [14-16].

This paper focuses on the influence of different quantities of sucrose on changes in yeast count, total sugar content, ethanol content, titratable acidity, and color parameters during fermentation. Furthermore, the volatile compounds in the musts and wines at the end of fermentation were identified and quantified by solid-phase microextraction with gas chromatography-mass spectrometry (SPME-GCMS) and the aromatic profiles of the wines were evaluated. The objective of this study was to evaluate the relevance of adding sucrose and to investigate the resultant characteristics of the "Shuangyou" wine aroma.

\section{Materials and Methods}

2.1. Sample Collection and Vinification. Some ripe grapes of the "Shuangyou" cultivar were picked by hand in Jian County (Jilin Province, China) during the 2015 harvest season. The vinification process of red wine employed follows methods reported in literature $[21,26]$. The stalks were eliminated before the berries were crushed manually and the musts were then transferred into a glass fermenter ( $5 \mathrm{~L}$, loading volume: $\sim 70-80 \%)$. Next, $5 \%$ sulfurous acid was added to reach a concentration of $50 \mathrm{mg} / \mathrm{L} \mathrm{SO}_{2}$. The sugar concentration in excellent quality of grape cultivars ranges from 100 to $250 \mathrm{~g} / \mathrm{L}$ [10]. On the other hand, "Shuangyou" grape berries have a total sugar content of only $87.75 \mathrm{~g} / \mathrm{L}$ (Table 1). Thus, different proportions of food grade sucrose $(20,60$, and $100 \mathrm{~g} / \mathrm{L}$; variables) were added to the musts. No sucrose was added in the control. Each must sample was next inoculated with $0.1 \%$ of a commercial dry yeast strain (RV171, Angel Yeast Co., Ltd, Yichang, China) for better fermentation [27]. The dry yeast strains were activated and precultured in synthetic grape must media $(110 \mathrm{~g} / \mathrm{L}$ glucose, $110 \mathrm{~g} / \mathrm{L}$ fructose, $3 \mathrm{~g} / \mathrm{L}$ tartaric acid, $0.3 \mathrm{~g} / \mathrm{L}$ malic acid, $0.5 \mathrm{~g} / \mathrm{L}$ ammonium chloride, $0.6 \mathrm{~g} / \mathrm{L}$ yeast extract, $2 \mathrm{~g} / \mathrm{L}$ tannins, $2 \mathrm{~g} / \mathrm{L} \mathrm{KH}_{2} \mathrm{PO}_{4}$, and $\left.0.2 \mathrm{~g} / \mathrm{L} \mathrm{MgSO}_{4} \cdot 7 \mathrm{H}_{2} \mathrm{O}, \mathrm{pH} 3.4\right)$ at $1 \times$ $10^{6}$ colony-forming units $(\mathrm{CFU}) / \mathrm{mL}$ before inoculation. The must samples were adequately mixed manually every day. After 4 days of maceration, the grape skins were separated from the wine. Finally, alcoholic fermentation was conducted at $18 \pm 2^{\circ} \mathrm{C}$ for 20 days. The physicochemical parameters and yeast counts of the wine samples were analyzed every 2 days until a total sugar content of $<4 \mathrm{~g} / \mathrm{L}$ was reached.

2.2. Yeast Counts and Standard Chemical Parameters Analysis. The enumeration of yeast was carried out using yeastpeptone-dextrose (YPD: $20 \mathrm{~g} / \mathrm{L}$ glucose, $20 \mathrm{~g} / \mathrm{L}$ peptone, $10 \mathrm{~g} / \mathrm{L}$ yeast extract, and $20 \mathrm{~g} / \mathrm{L}$ agar) plates [28]. Standard chemical parameters (total sugar, ethanol, and titratable acidity) were determined according to the National Standard of the People's Republic of China (GB/T15038-2006, 2006) [22].

2.3. Color Parameter Analysis. The chromatic parameters in the CIELAB color space consisted in recording the absorbance values at four specific wavelengths $(450,520,570$, and $630 \mathrm{~nm}$ ) and using them to compute the tristimulus measurements [29]. The main CIELAB parameters $a^{*}, b^{*}$, and $L^{*}$ were calculated; $a^{*}$ represents the difference between green $\left(a^{*}<0\right)$ and red $\left(a^{*}>0\right), b^{*}$ indicates the difference between blue $\left(b^{*}<0\right)$ and yellow $\left(b^{*}>0\right)$, and $L^{*}$ describes the lightness of the color $\left(L^{*}=0\right.$ black and $L^{*}=100$ colorless).

2.4. Volatile Compounds Analysis. Volatile compounds were produced by headspace- (HS-) SPME. 4-Methyl-2-pentanol was used as the internal standard substance for semiquantification. The wine sample $(8 \mathrm{~mL}), 0.8 \mathrm{~g} \mathrm{NaCl}$, and $30 \mu \mathrm{L}$ 4-methyl-2-pentanol $(3.2 \mathrm{~g} / \mathrm{L})$ were placed into a $15 \mathrm{~mL}$ sample vial that was sealed with a polytetrafluorethylene (PTFE)/silicone septum (Supelco, Bellefonte, PA, USA). The samples were agitated with a magnetic stirring bar and preconditioned at $45^{\circ} \mathrm{C}$ for $10 \mathrm{~min}$ in the vial. A $50 / 30 \mu \mathrm{m}$ divinylbenzene/carboxen/polymethylsiloxane (DVB/CAR/ PDMS) fiber (Supelco, length $=2 \mathrm{~cm}$ ) was exposed to the 
headspace of the vial for $30 \mathrm{~min}$ at $45^{\circ} \mathrm{C}$; the volatile compounds were absorbed by the fiber. All SPME injections were immediately carried out in splitless mode at $250^{\circ} \mathrm{C}$ for $10 \mathrm{~min}$.

The volatile compounds were analyzed by GC-MS (Thermo Fisher Science, Trace1300/ ISQ-LT, USA). Thermo TraceFinder easy file sharing (EFS) software was used to operate the system (chromatography column: HP-5 $30 \mathrm{~m}$ $\times 0.25 \mathrm{~mm} \times 0.25 \mu \mathrm{m}$; carrier gas: helium; and flow rate: $1 \mathrm{~mL} / \mathrm{min}$ ) and was conducted according to the following program: $32^{\circ} \mathrm{C}$ for $3 \mathrm{~min}$, subsequent raise to $50^{\circ} \mathrm{C}$ at $2^{\circ} \mathrm{C} / \mathrm{min}$ for $2 \mathrm{~min}$, and further raise to $230^{\circ} \mathrm{C}$ at $4^{\circ} \mathrm{C} / \mathrm{min}$ for $8 \mathrm{~min}$. The MS analysis conditions were as follows: mass spectra were acquired in electron impact mode $(70 \mathrm{eV})$ and scanned fully at a range of $30-450 \mathrm{~m} / \mathrm{z}$ at $1 \mathrm{~s}$ intervals (ionization source: $\mathrm{EI}^{+}$; transfer line and ion source temperatures: 280 and $230^{\circ} \mathrm{C}$, respectively; filament flow: $0.25 \mu \mathrm{A}$; detector voltage $=350 \mathrm{~V}$ ) $[30,31]$.

The typical samples on day 0 and day 18 were chosen and were studied by GC-MS. After that, the volatile compounds were identified by comparing the retention times and mass spectra of the sample with those found in the mass spectrometer database (NIST 2014) or in literature. Semiquantitative determinations ( $\mathrm{mg} / \mathrm{L}$ of wine) were calculated by the internal standard method (Table 2).

2.5. Odor Activity Values (OAVs). The contribution of volatile compounds to the wine samples was evaluated by determining the OAV of the wine, a measure of importance to typical aromas of wine. Volatile compounds present in wine with OAVs $>1$ are generally considered to be likely contributors to the characteristic aroma of the wine [32]. OAVs are calculated as the ratio between the concentration of an individual compound and the perception threshold reported in literature (Table 3) [18-20].

2.6. Statistical Analysis. All analyses were performed in duplicate and the afforded average values for each sample (three samples per treatment) were used to calculate the mean concentration values and their standard deviations. Significant differences were assessed with one-way analysis of variance (ANOVA), while statistical differences between the means were evaluated using least-significant difference (LSD) analysis at the $P=0.05$ level. Statistical data processing was performed using SPSS Statistics 19.0 for Windows (IBM, NY, USA) software.

\section{Results and Discussion}

3.1. Yeast Growth. The growth behavior of the yeast culture is illustrated in Figure 1. The cell counts of all four fermentation processes increased from $\sim 0.5 \times 10^{5} \mathrm{CFU} / \mathrm{mL}$ to $\sim 1 \times$ $10^{8} \mathrm{CFU} / \mathrm{mL}$. Cell counts for the controls and samples with 20 and $60 \mathrm{~g} / \mathrm{L}$ added sucrose reached a maximum $(0.464 \times$ $10^{8}, 1.38 \times 10^{8}$, and $1.51 \times 10^{8} \mathrm{CFU} / \mathrm{mL}$, resp.) on day 6 , while the sample with $100 \mathrm{~g} / \mathrm{L}$ added sucrose reached the maximum $\left(1.59 \times 10^{8} \mathrm{CFU} / \mathrm{mL}\right)$ on day 8 . Notably, during the first 6 days of fermentation, the growth rates were similar for all the samples. A lower growth rate was observed in the controls,

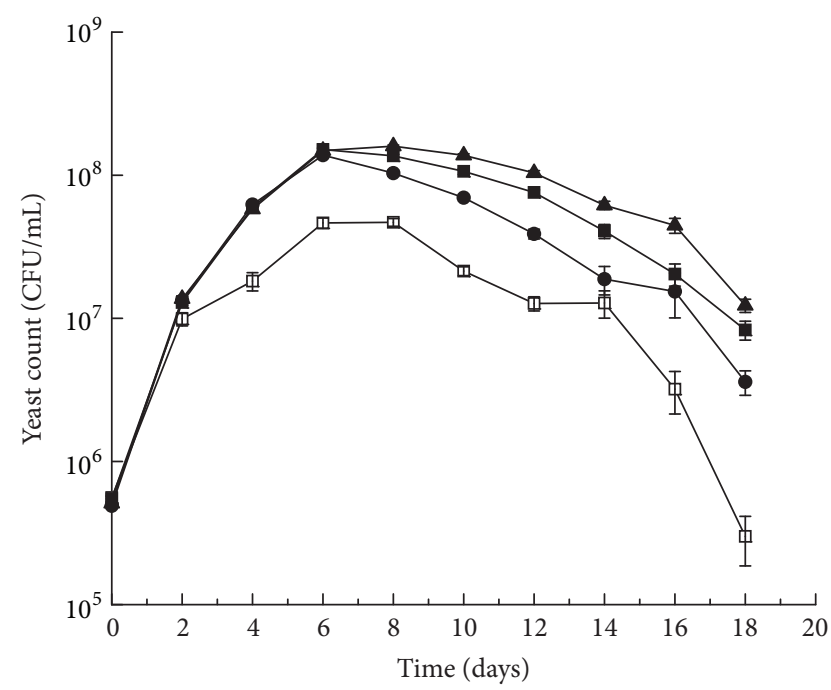

FIGURE 1: Growth of yeast cells of "Shuangyou" wines added with $20(\bullet), 60(\square)$, and $100(\Delta)$ g/L sucrose and controls ( $\square)$ during fermentation.

probably due to less sugar being available for yeast breeding [12]. These results are in agreement with other studies that have reported that sugar-rich environments are important for yeast cell growth in wine fermentation $[11,12]$. After reaching the maximum values, the yeast culture in all the fermentation processes experienced a fast decrease in cell counts. This decline was more marked in the controls where the final cell count was less than that of the initial musts (Table 1). The faster death rate of the yeast cells in the controls indicates that the lack of nutrients in the later stage of fermentation as well as the accumulation of ethanol and other inhibitory substances in the wine could lead to a decrease in yeast cells.

3.2. Sugar Consumption. The changes in total sugar content observed in the different samples during their fermentation processes are displayed in Figure 2(a). The total sugar content in the controls and the sample with $20 \mathrm{~g} / \mathrm{L}$ added sucrose decreased continuously on the first 6 days of fermentation and remained stable thereafter. Similarly, the total sugar content in the samples with 60 and $100 \mathrm{~g} / \mathrm{L}$ added sucrose experienced a faster decline in the first 12 days; this was followed by a slight decrease to 1.21 and $3.00 \mathrm{~g} / \mathrm{L}$, respectively (Table 1). In fact, the yeast strains yielded the extracellular invertase that hydrolyzed sucrose into a reducing sugar [9]. A large proportion of the reducing sugar was then assimilated by the yeast into ethanol and carbon dioxide [10]. Subsequently, the rate of sugar consumption decreased while the yeast cells died quickly [33]. Thus, the rate of sugar consumption was concluded to be related to the rate of yeast growth [34]. In addition, during fermentation, the highest sugar consumption was observed in the sample with the highest amount $(100 \mathrm{~g} / \mathrm{L})$ of added sucrose (Figure 2(a) and Table 1). This indicates that the fermentative lifestyle could exhibit a growth advantage in sugar-rich environments due to a higher rate of sugar conversion and energy production [35]. 


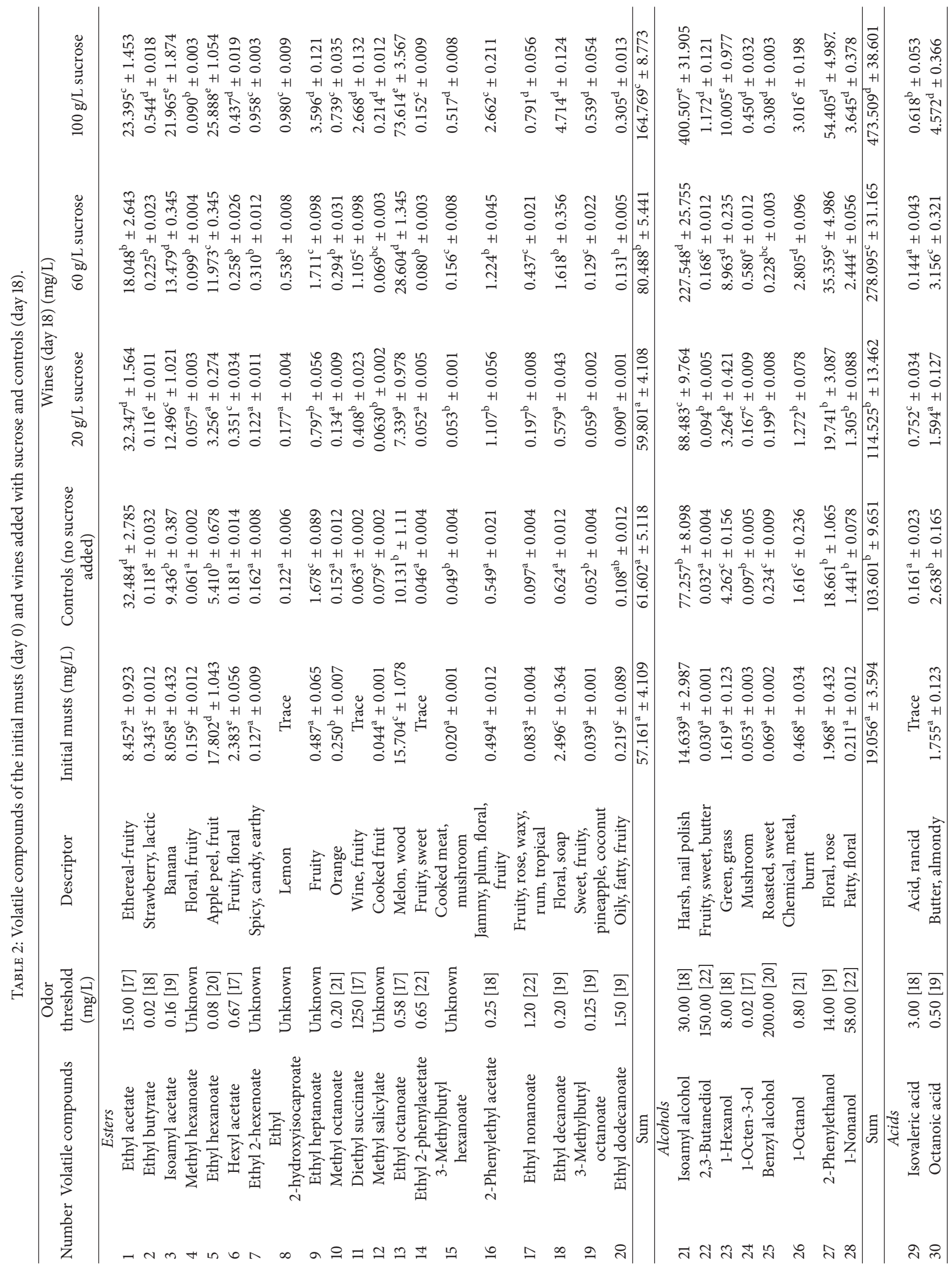




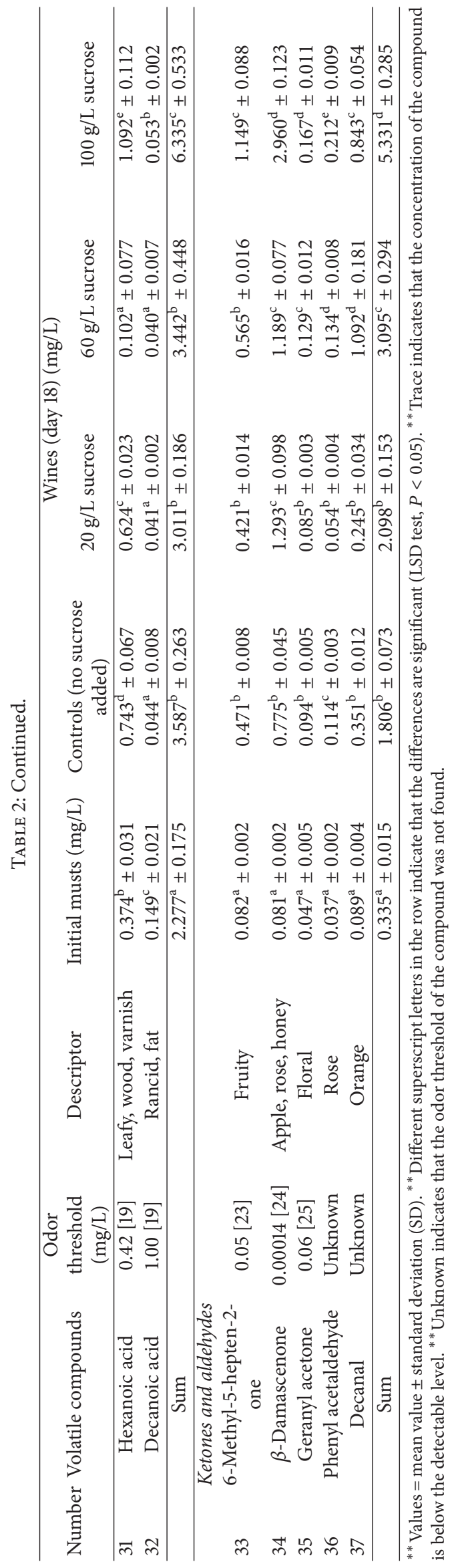


TABLE 3: Odour activity values (OAVs) of major volatile compounds in the initial musts (day 0 ) and wines added with sucrose and controls (day 18).

\begin{tabular}{|c|c|c|c|c|c|}
\hline \multirow{2}{*}{ Volatile compounds } & \multirow{2}{*}{ Initial musts (day 0) } & \multicolumn{4}{|c|}{ Wines (day 18) } \\
\hline & & Controls (no sucrose added) & $20 \mathrm{~g} / \mathrm{L}$ sucrose & $60 \mathrm{~g} / \mathrm{L}$ sucrose & $100 \mathrm{~g} / \mathrm{L}$ sucrose \\
\hline \multicolumn{6}{|l|}{ Esters } \\
\hline Ethyl acetate & $0.563 \pm 0.062$ & $2.166 \pm 0.186$ & $2.156 \pm 0.104$ & $1.203 \pm 0.176$ & $1.560 \pm 0.097$ \\
\hline Ethyl butyrate & $17.159 \pm 0.600$ & $5.892 \pm 1.600$ & $5.822 \pm 0.550$ & $11.226 \pm 1.150$ & $27.189 \pm 0.900$ \\
\hline 3-Methylbutyl acetate & $50.361 \pm 2.700$ & $58.976 \pm 2.419$ & $78.097 \pm 6.381$ & $84.246 \pm 2.156$ & $137.281 \pm 11.713$ \\
\hline Ethyl hexanoate & $222.528 \pm 13.038$ & $67.631 \pm 8.475$ & $40.705 \pm 3.425$ & $149.664 \pm 4.313$ & $323.604 \pm 13.175$ \\
\hline Hexyl acetate & $3.556 \pm 0.084$ & $0.270 \pm 0.021$ & $0.524 \pm 0.051$ & $0.385 \pm 0.039$ & $0.652 \pm 0.028$ \\
\hline Methyl octanoate & $1.249 \pm 0.035$ & $0.759 \pm 0.060$ & $0.672 \pm 0.045$ & $1.469 \pm 0.155$ & $3.697 \pm 0.175$ \\
\hline Ethyl octanoate & $27.076 \pm 1.859$ & $17.467 \pm 1.914$ & $12.654 \pm 1.686$ & $49.317 \pm 2.319$ & $126.921 \pm 6.150$ \\
\hline Ethyl 2-phenylacetate & $0.000 \pm 0.002$ & $0.071 \pm 0.006$ & $0.079 \pm 0.008$ & $0.123 \pm 0.005$ & $0.234 \pm 0.014$ \\
\hline 2-Phenylethyl acetate & $1.977 \pm 0.048$ & $2.197 \pm 0.084$ & $4.427 \pm 0.224$ & $4.897 \pm 0.180$ & $10.648 \pm 0.844$ \\
\hline Ethyl nonanoate & $0.069 \pm 0.003$ & $0.081 \pm 0.003$ & $0.164 \pm 0.007$ & $0.364 \pm 0.018$ & $0.659 \pm 0.047$ \\
\hline Ethyl decanoate & $12.480 \pm 1.820$ & $3.118 \pm 0.060$ & $2.893 \pm 0.215$ & $8.091 \pm 1.780$ & $23.569 \pm 0.620$ \\
\hline 3-Methylbutyl octanoate & $0.313 \pm 0.008$ & $0.412 \pm 0.032$ & $0.473 \pm 0.016$ & $1.033 \pm 0.176$ & $4.310 \pm 0.432$ \\
\hline Ethyl dodecanoate & $0.146 \pm 0.059$ & $0.072 \pm 0.008$ & $0.060 \pm 0.001$ & $0.087 \pm 0.003$ & $0.203 \pm 0.009$ \\
\hline \multicolumn{6}{|l|}{ Alcohols } \\
\hline Isoamyl alcohol & $0.488 \pm 0.100$ & $2.575 \pm 0.270$ & $2.949 \pm 0.325$ & $7.585 \pm 0.859$ & $13.350 \pm 1.064$ \\
\hline 1-Hexanol & $0.202 \pm 0.015$ & $0.533 \pm 0.020$ & $0.408 \pm 0.053$ & $1.120 \pm 0.029$ & $1.251 \pm 0.122$ \\
\hline 1-Octen-3-ol & $2.637 \pm 0.150$ & $4.857 \pm 0.250$ & $8.353 \pm 0.450$ & $29.000 \pm 0.600$ & $22.489 \pm 1.600$ \\
\hline 1-Octanol & $0.585 \pm 0.043$ & $2.021 \pm 0.295$ & $1.590 \pm 0.098$ & $3.506 \pm 0.120$ & $3.770 \pm 0.248$ \\
\hline 2-Phenylethanol & $0.141 \pm 0.031$ & $1.333 \pm 0.076$ & $1.410 \pm 0.221$ & $2.526 \pm 0.356$ & $3.886 \pm 0.356$ \\
\hline 1-Nonanol & $0.004 \pm 0.000$ & $0.025 \pm 0.001$ & $0.023 \pm 0.002$ & $0.042 \pm 0.001$ & $0.063 \pm 0.007$ \\
\hline \multicolumn{6}{|l|}{ Acids } \\
\hline Isovaleric acid & $0.000 \pm 0.000$ & $0.054 \pm 0.008$ & $0.251 \pm 0.011$ & $0.048 \pm 0.014$ & $0.206 \pm 0.018$ \\
\hline Octanoic acid & $3.509 \pm 0.246$ & $5.277 \pm 0.330$ & $3.188 \pm 0.254$ & $6.313 \pm 0.642$ & $9.144 \pm 0.732$ \\
\hline Hexanoic acid & $0.890 \pm 0.074$ & $1.770 \pm 0.160$ & $1.487 \pm 0.055$ & $0.242 \pm 0.183$ & $2.601 \pm 0.267$ \\
\hline Decanoic acid & $0.149 \pm 0.021$ & $0.044 \pm 0.008$ & $0.041 \pm 0.002$ & $0.040 \pm 0.007$ & $0.053 \pm 0.002$ \\
\hline \multicolumn{6}{|l|}{ Ketones } \\
\hline 6-Methyl-5-hepten-2-one & $1.64 \pm 0.04$ & $9.42 \pm 0.16$ & $8.42 \pm 0.28$ & $11.30 \pm 0.32$ & $22.98 \pm 1.76$ \\
\hline$\beta$-Damascenone & $578.57 \pm 14.23$ & $5535.714 \pm 330.454$ & $9235.714 \pm 123.876$ & $8492.851 \pm 165.232$ & $21142.857 \pm 465.759$ \\
\hline Geranyl acetone & $0.783 \pm 0.083$ & $1.567 \pm 0.067$ & $1.417 \pm 0.033$ & $2.150 \pm 0.210$ & $2.783 \pm 0.183$ \\
\hline
\end{tabular}

${ }^{* *}$ Values $=$ mean values \pm standard deviation $(\mathrm{SD})$.

3.3. Ethanol Production. The ethanol changes observed in the different samples during their fermentation processes are presented in Figure 2(b). The ethanol in all the fermentation processes increased sharply during the first 8 days of fermentation. Subsequently, the samples with 60 and $100 \mathrm{~g} / \mathrm{L}$ added sucrose exhibited a marked increase in ethanol. Conversely, the sample with $20 \mathrm{~g} / \mathrm{L}$ added sucrose and the controls remained stable. The sample with $100 \mathrm{~g} / \mathrm{L}$ added sucrose exhibited the highest increase in ethanol $(10.27 \% \mathrm{v} / \mathrm{v})$ and the fastest rate of production. This was followed by the samples with $60 \mathrm{~g} / \mathrm{L}$ added sucrose, $20 \mathrm{~g} / \mathrm{L}$ added sucrose, and the controls, respectively (Figure 2(b) and Table 1). Compared to the samples with added sucrose, the ethanol contents in the controls were low $(4.9 \% \mathrm{v} / \mathrm{v})$ throughout fermentation, illustrating that the initial musts contained less sugar $(87.75 \mathrm{~g} / \mathrm{L})$ for the yeasts to assimilate into ethanol (Table 1). Thus, we concluded that if the musts contained a higher sugar concentration, the yeast would have yielded more ethanol. This is in agreement with the results obtained in previous studies $[36,37]$.

3.4. Acid Consumption. The changes in titratable acidity for the different fermentation process of the different samples are illustrated in Figure 2(c). The titratable acidity in all the samples decreased from $\sim 15 \mathrm{~g} / \mathrm{L}$ to $\sim 13 \mathrm{~g} / \mathrm{L}$ (Table 1). This decrease was attributed to the reduction in tartaric acid and is related to the complexation of this acid with other compounds (such as potassium to form potassium bitartrate). In addition, this result was justified by the reduction in the volatile acid content in the musts during fermentation [38]. The titratable acidity for the samples with 60 and $100 \mathrm{~g} / \mathrm{L}$ added sucrose decreased slightly during the first 10 days of fermentation (Figure 2(c)). No significant changes were observed in the sugar-rich environments, probably due to the 


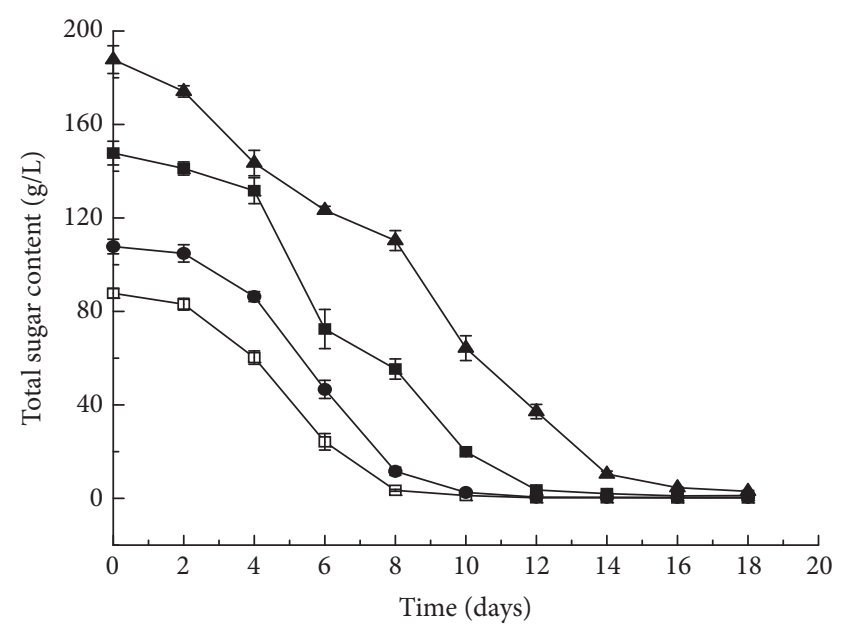

(a)

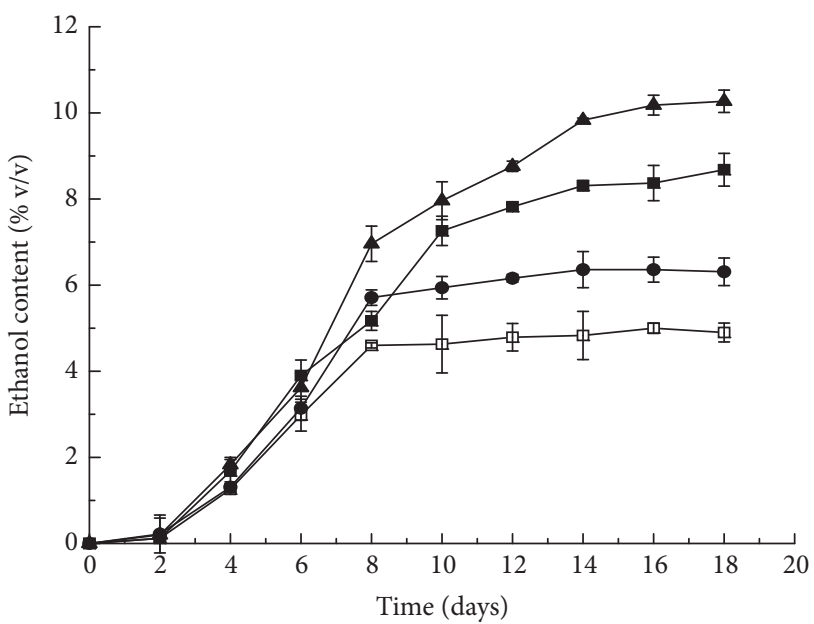

(b)

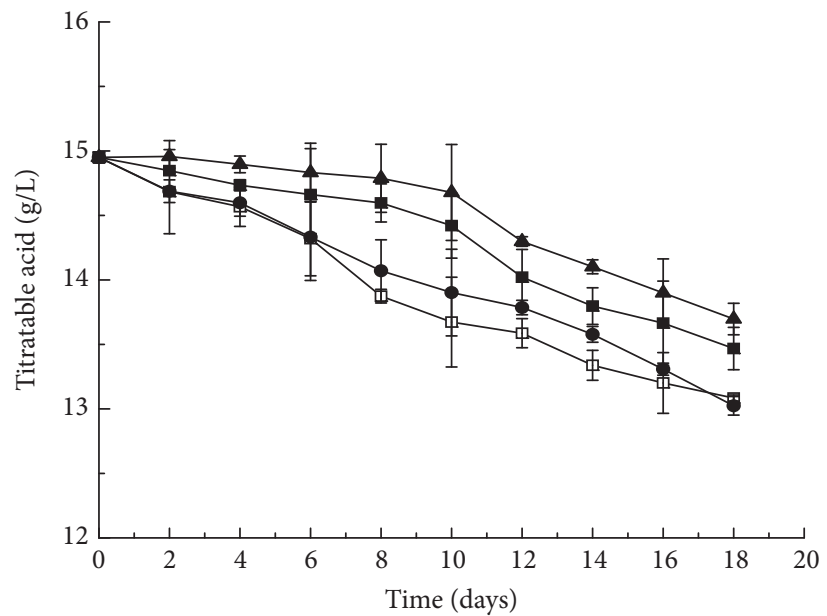

(c)

FIGURE 2: Changes of chemical parameters including total sugar content (a), ethanol content (b), and titrable acidity (c) of "Shuangyou" wines added with $20(\bullet), 60(\mathbf{\square})$, and $100(\mathbf{\Delta})$ g/L sucrose and controls () during fermentation.

excretion of the intermediate ( $\alpha$-ketoglutaric acid, succinic acid, acetoin, diacetyl, etc.) from the tricarboxylic acid (TCA) [39].

3.5. Color Evolution. The changes in color parameters $\left[a^{*}\right.$ (a), $b^{*}$ (b), $L^{*}$ (c)] in the different fermentation samples are displayed in Figure 3. For all the samples, an increase in $a^{*}$ (red/green) and a decrease in $b^{*}$ (yellow/blue) and $L^{*}$ (lightness) were observed on the first four days of the fermentation process. These changes were attributed to the mass of the pigments that leach from the grape skin during maceration (4 days) [40]. After this process, a slight decrease in $a^{*}$ was observed. This was due to the formation of a more complex mixture of pigments that are involved in the burgundy color of red wine [41]. Conversely, the value for $b^{*}$ increased sharply. This increase was more marked in the samples with 60 and $100 \mathrm{~g} / \mathrm{L}$ added sucrose and is likely due to the formation of yellow-orange pigments during the later stages of fermentation that are relevant to sugar assimilation [42]. Moreover, an increase in $L^{*}$, attributed to the precipitation of insoluble substances in the wine samples, was also observed. Notably, the wine from the musts with 60 and $100 \mathrm{~g} / \mathrm{L}$ added sucrose exhibited the highest $a^{*}$ and $b^{*}$ values (Table 1 ). This indicated that the main CIELAB parameters of the wine were related to the sugar concentration added in the must samples.

3.6. Volatile Compounds. The concentration of volatile compounds and the OAVs of the major volatile compounds in the different fermentation samples are listed in Tables 2 and 3, respectively. A total of 37 volatile compounds, including esters, alcohols, acids, ketones, and aldehydes, were identified and quantified. Among these compounds, alcohols were the most abundant in the wine samples (samples with added sucrose and the controls), while esters were the most abundant compounds in the musts (Table 2).

Because they are the primary source of fruity and floral aromas, esters are an important group of volatile compounds that greatly influence the wine aroma [43-45]. The results revealed that the wines were rich in esters; 20 esters were 


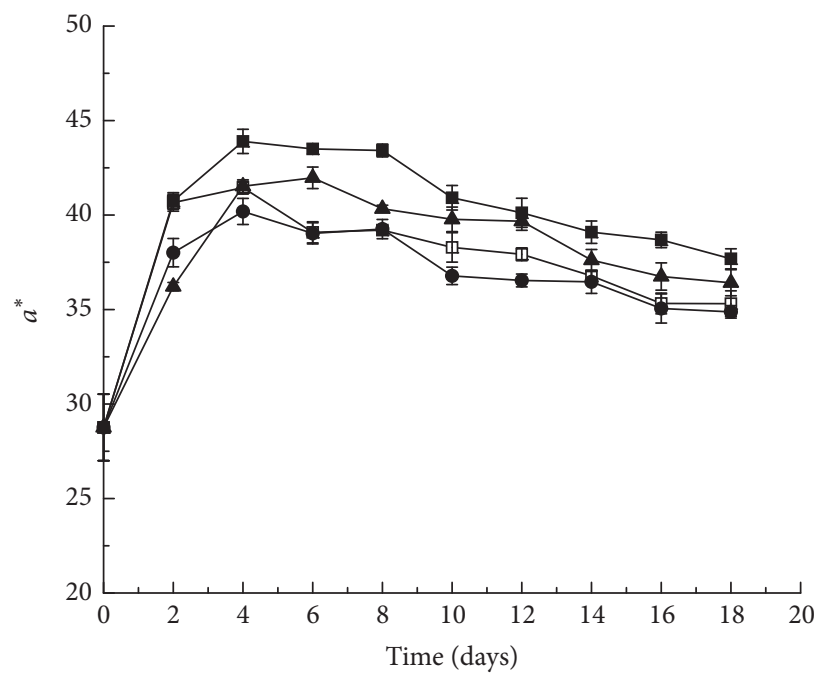

(a)

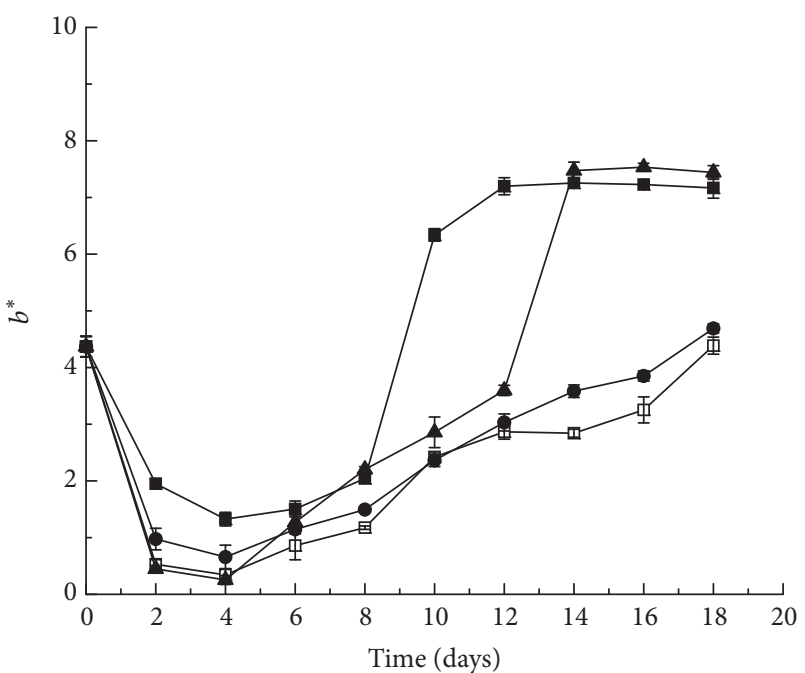

(b)

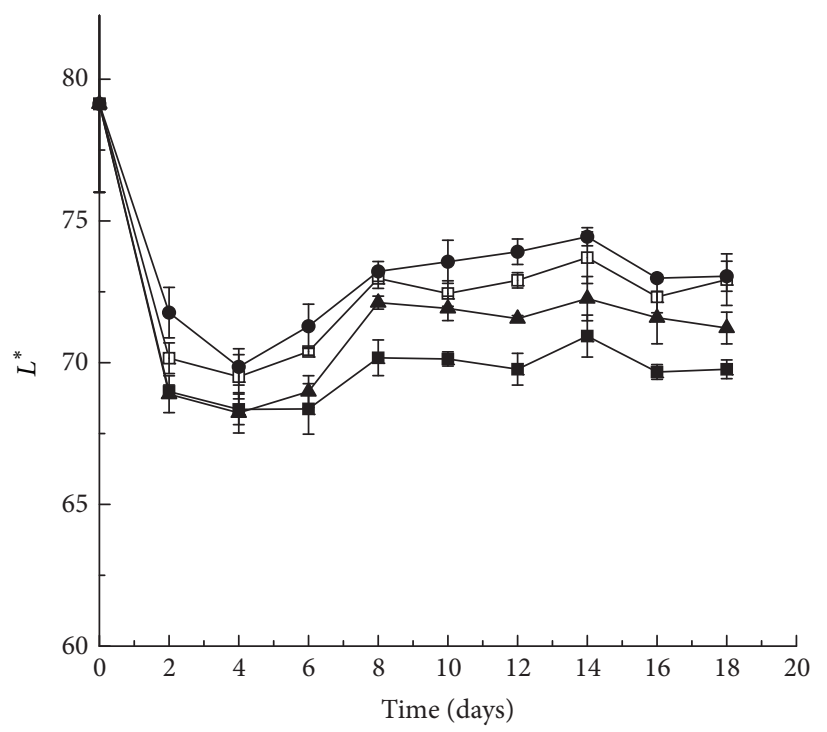

(c)

Figure 3: Changes of the color parameters including: $a^{*}$ (red/green, (a)), $b^{*}$ (yellow/blue, (b)), and $L^{*}$ (lightness, (c)) of "Shuangyou" wines added with $20(\bullet), 60(\mathbf{\bullet})$, and $100(\mathbf{\Delta}) \mathrm{g} / \mathrm{L}$ sucrose and controls ( $\square)$ during fermentation.

identified (Table 3), 9 of which contribute to the wine aroma directly or synergistically due to their relatively high OAVs $(>1)$. Ethyl acetate, ethyl octanoate, ethyl hexanoate, and isoamyl acetate were the dominant compounds. Compared to the controls, the concentrations of the total esters and the odor activity values of esters (OAVs $>1$ ) in the wines added sucrose were higher. Furthermore, the wines with $100 \mathrm{~g} / \mathrm{L}$ added sucrose during fermentation exhibited the highest concentration of total esters $(164.77 \mathrm{mg} / \mathrm{L})$. The odor activity values of esters in the wines with $100 \mathrm{~g} / \mathrm{L}$ added sucrose were 2.33-10.46 times higher than that of the controls. Previous studies have reported that most esters are secondary metabolites whose formation in wine mainly depends on the number of alcohols and acids that are generated by yeast assimilated sugar during alcoholic fermentation [1416]. Thus, during esterification, a larger number of esters formed in the wine samples that contained a high sugar content; these results were in agreement with the results in this study.

In terms of alcohols, significant differences were observed between the wines with added sucrose and the controls. The wines from the samples with $100 \mathrm{~g} / \mathrm{L}$ added sucrose comprised the highest concentration of total alcohols $(474.51 \mathrm{mg} / \mathrm{L})$. This demonstrates that the addition of sucrose improves the alcohol concentration in wines. $\mathrm{C}_{4}, \mathrm{C}_{5}$, and $\mathrm{C}_{6}$ alcohols typically exhibit a number of characteristics (harsh, fruity, green, and grass aromas) that negatively affect the wine aroma [14]; $\mathrm{C}_{4}, \mathrm{C}_{5}$, and $\mathrm{C}_{6}$ alcohols in this study were identified as 2,3-butanediol, isoamyl alcohol, and 1-hexanol, respectively. The highest alcohol concentrations reached at the end of the fermentation process were observed in the wine samples with $100 \mathrm{~g} / \mathrm{L}$ added sucrose (2,3-butanediol 
$=1.17 \mathrm{mg} / \mathrm{L}$, isoamyl alcohol $=400.51 \mathrm{mg} / \mathrm{L}$, and 1-hexanol $=10.01 \mathrm{mg} / \mathrm{L}$ ). These were followed, in descending order, by the samples with $60 \mathrm{~g} / \mathrm{L}$ added sucrose, $20 \mathrm{~g} / \mathrm{L}$ added sucrose, controls, and musts (Table 2). The increase of these compounds in sugar-rich environments may be due to extra oxygen dissolved in the must samples. Thus, the more oxygen is dissolved in the musts, the more $\mathrm{C}_{6}$ aldehydes would be generated through the degeneration of lipid acids. In addition, the results in our study demonstrated that the concentrations of isoamyl alcohol and 1-hexanol in wines (Table 3) exceeded their threshold (OAVs > 1). The odor activity values of isoamyl alcohol and 1-hexanol in the wines with $100 \mathrm{~g} / \mathrm{L}$ added sucrose were 5.18 and 2.35 times higher, respectively, than that of the controls. Higher alcohols $\left(>C_{6}\right.$, fusel alcohols) usually have a strong and pungent odor character. These compounds are secondary products of yeast alcoholic fermentation and can have a positive or negative effect on wine aroma depending on their concentration. At low concentrations $(<300 \mathrm{mg} / \mathrm{L})$, they can contribute to the desirable complexity of the wine aroma. On the other hand, at higher concentrations $(>400 \mathrm{mg} / \mathrm{L})$, they become negative aroma quality factors [19]. Five higher alcohols were identified in this study, namely, 1-octen-3-ol, benzyl alcohol, 1-octanol, 2-phenylethanol, and 1-nonanol (Table 2); these alcohols usually have rose, floral, mushroom, and burnt aromas. The higher concentrations of the different alcohols in all treatments were $<400 \mathrm{mg} / \mathrm{L}$ (at $0.45-55.44 \mathrm{mg} / \mathrm{L}$, Table 2). At the end of fermentation, the wines with $100 \mathrm{~g} / \mathrm{L}$ added sucrose exhibited the highest total concentration. Furthermore, the results revealed that the concentrations of 1-octen-3-ol, 1octanol, and 2-phenylethanol (Table 3) in the wine samples all exceeded their threshold values (OAVs $>1$ ). The odor activity values of 1-octen-3-ol, 1-octanol, and 2-phenylethanol in the wines with $100 \mathrm{~g} / \mathrm{L}$ added sucrose were $4.63,1.87$, and 2.92 times higher, respectively, than that of the controls. This effect indicates that the addition of sucrose strengthens the desired wine aroma.

Previous studies have shown that the production and presence of fatty acids depends on the composition of the grape musts and the fermentation conditions [46]. Volatile fatty acids have a negative effect on the wine aroma when above their thresholds [19]. Nevertheless, they still have a harsh, fruity, green, grass aroma character that causes a complex wine bouquet even when they exceed the threshold values (OAVs $>1)$. Four fatty acids, including octanoic acid, hexanoic acid, decanoic acid, and isovaleric acid, were identified in the wines in this study (Table 2). Among these, octanoic acid was the dominant acid, followed by hexanoic acid, isovaleric acid, and decanoic acid, respectively. Except for decanoic acid, the amount of fatty acids in the wine samples was higher than that observed in the musts. Thus, these compounds were thought to be generated from the yeast assimilated sugar during the fermentation process. Conversely, decanoic acid formed esters, resulting in a decrease in its content at the end of fermentation. Furthermore, the wine sample with $100 \mathrm{~g} / \mathrm{L}$ of added sucrose had the highest amounts of each fatty acid except decanoic acid. Moreover, the concentration of octanoic acid and hexanoic acid (Table 3) in the wine samples significantly exceeded their threshold values (OAVs $>1)$. The odor activity values of octanoic acid and hexanoic acid in the wines with $100 \mathrm{~g} / \mathrm{L}$ added sucrose were 1.73 and 1.47 times higher, respectively, than that of the controls. Usually, the presence of fatty acids in wine is related to unpleasant odors, even though these compounds do not have a direct negative effect on the flavor of the wines since they are present in low concentrations. The wine samples with added sucrose produced higher relative amounts of fatty acids that have the potential to destroy the wine aroma.

Other volatile compounds found in the wine samples included three ketones and two aldehydes (6-methyl5 -hepten-2-one, $\beta$-damascenone, geranylacetone, phenyl acetaldehyde, and decanal, resp.). The amounts of these compounds were higher in the wines than in the musts. This indicates that these compounds are generated by yeast assimilated sugar during fermentation. Compared to the controls, the ketones and aldehydes in the wine samples with $100 \mathrm{~g} / \mathrm{L}$ added sucrose comprised the largest amounts of these compounds (Table 2). Furthermore, the concentration of 6methyl-5-hepten-2-one, $\beta$-damascenone, and geranylacetone (Table 3 ) in the wine samples significantly exceeded their threshold values (OAVs $>1)$. The odor activity values of 6methyl-5-hepten-2-one, $\beta$-damascenone, and geranylacetone in the wines with $100 \mathrm{~g} / \mathrm{L}$ added sucrose were $2.44,3.82$, and 1.78 times higher, respectively, than that of the controls.

\section{Conclusions}

The results of this work reveal that the addition of sucrose during the fermentation process has a significant influence on the physicochemical properties and volatile compounds of "Shuangyou" wine. The study indicated that yeast could convert sucrose into a reducing sugar that was then assimilated into alcohol by yeast. Therefore, we concluded that the addition of sucrose contributes to yeast growth and alcohol production. The addition of $100 \mathrm{~g} / \mathrm{L}$ sucrose afforded the highest concentrations of total sugar and ethanol at the end of fermentation that theoretically could be metabolized by the yeast. The titratable acidity of all the fermentation processes decreased slightly. Moreover, the higher amounts of added sucrose ( 60 or $100 \mathrm{~g} / \mathrm{L}$ ) altered the color of the wine samples, making them darker and deeper than that those with lower or no sucrose. A total of 37 individual aroma compounds rich in different volatile compounds (esters, alcohol, fatty acids, ketones, and aldehydes) were detected in "Shuangyou" wines by HS-GC-MS analysis. The addition of sucrose influenced the aroma concentration of these wines. Furthermore, the addition of $100 \mathrm{~g} / \mathrm{L}$ sucrose was sufficient to improve the concentrations of the aroma compounds. This was evidenced by volatile quantification and OAVs evaluation. Most of the aroma compounds in the wine samples with the highest amount of added sucrose made a positive impact on the wine quality, especially reinforcing the global aromatic complexity of the wine. In addition, sucrose addition seems to produce a stronger pungent taste impact during fermentation, based on the results of the present study. Hence, it should elucidate in greater detail the relationship between volatile aroma and poor sensory quality of wines. Technologies like sensory 
panel may be of a great advantage to researchers when dealing with samples with unpleasant taste. Further study is needed to confirm our hypothesis.

\section{Additional Points}

Practical Applications. The "Shuangyou" grape cultivar is widely cultivated both in western and in northeastern China and its grapes are a source of grape juice and high-quality red wine. Compared to $V$. vinifera wines, $V$. amurensis wines have a bright ruby red color, fine fragrant aroma, and a mellow and full-bodied taste. However, this wine is also rich in bioactive substances that often impart high acidity, a very sour taste, and low alcohol content, making it less popular. The results reveal that when sucrose is added during the winemaking process, so that the sugar concentration reaches concentrations observed in more commonly grown wine, the quality of "Shuangyou" wines is improved. This increases the potential popularity of these wines.

\section{Conflicts of Interest}

The authors declare that they have no conflicts of interest.

\section{Acknowledgments}

The authors would like to acknowledge Editage for English language editing. This research was supported by the Project of Jilin Province Science and Technology Agency (Grant no. 20150101117JC to H. Liu) and Jilin Province Education Agency (Grant no. 2016246 to H. Liu).

\section{References}

[1] Y. Xiong and W. M. Zhang, "Research and utilization of cold resistance of chinese wild Vitis," Journal of Anhui Agricultural. Sciences, vol. 35, no. 11, pp. 3238-3239, 2007.

[2] R. G. Song, C. Y. Li, J. Ai et al., "Industrial development and countermeasure V. amurensis Rupr. in China," Sino-overseas Grapevine \& Wine, no. 4, pp. 6-9, 2002.

[3] J. M. Li and P. C. He, "Study on important wine making quality character of Chinese wild Vitis," Scientia. Agricultura Sinica, vol. 33, no. 1, pp. 17-23, 2000.

[4] Y. Chen, D. F. Chen, and S. L. Wang, "Analyse on amino acids and nutrient elements content in the seed of Vitis amurensis," Forestry Science Technology, vol. no. 5, pp. 55-56, 2008.

[5] H. X. Peng, R. L. Huang, and R. S. Pan, "Characteristics and viticulture of wild," no.1, pp. 30-34, 2000.

[6] H. J. Lv, L. G. Feng, and Y. L. Yan, "Study on the new techniques for decreasing the acidity of Vitis amurensis Rupr," Sino-overseas Grapevine Wine, vol. no. 1, pp. 42-43, 2005.

[7] J. F. Chen and B. Kremer, "The effect of wine deacidification with different methods," Sino-overseas Grapevine Wine, vol. no. 3, pp. 17-20, 2001.

[8] Z. D. Jiang, H. L. Nan, and H. Li, "Study on acid-degradation of dry wild grape wine," Liquor-Making Science Technology, vol. no. 12, pp. 47-49, 2008.

[9] S. Ostergaard, L. Olsson, and J. Nielsen, "Metabolic engineering of Saccharomyces cerevisiae," Microbiology and Molecular Biology Reviews, vol. 64, no. 1, pp. 34-50, 2000.
[10] A. Jordão, A. Vilela, and F. Cosme, "From Sugar of Grape to Alcohol of Wine: Sensorial Impact of Alcohol in Wine," Beverages, vol. 1, no. 4, pp. 292-310, 2015.

[11] R. Tofalo, C. Chaves-López, F. Di Fabio et al., "Molecular identification and osmotolerant profile of wine yeasts that ferment a high sugar grape must," International Journal of Food Microbiology, vol. 130, no. 3, pp. 179-187, 2009.

[12] J. Santos, M. J. Sousa, H. Cardoso et al., "Ethanol tolerance of sugar transport, and the rectification of stuck wine fermentations," Microbiology, vol. 154, no. 2, pp. 422-430, 2008.

[13] B. C. Childs, J. C. Bohlscheid, and C. G. Edwards, "Impact of available nitrogen and sugar concentration in musts on alcoholic fermentation and subsequent wine spoilage by Brettanomyces bruxellensis," Food Microbiology, vol. 46, pp. 604609, 2015.

[14] J. H. Swiegers and I. S. Pretorius, "Yeast modulation of wine flavor," Advances in Applied Microbiology, vol. 57, pp. 131-175, 2005.

[15] V. I. Petropulos, E. Bogeva, T. Stafilov et al., "Study of the influence of maceration time and oenological practices on the aroma profile of Vranec wines," Food Chemistry, vol. 165, pp. 506-514, 2014.

[16] R. D. Soares, J. E. Welke, K. P. Nicolli et al., "Monitoring the evolution of volatile compounds using gas chromatography during the stages of production of Moscatel sparkling wine," Food Chemistry, vol. 183, pp. 291-304, 2015.

[17] J. Wang, D. L. Capone, K. L. Wilkinson, and D. W. Jeffery, "Chemical and sensory profiles of rosé wines from Australia," Food Chemistry, vol. 196, pp. 682-693, 2016.

[18] H. Guth, "Quantitation and sensory studies of character impact odorants of different white wine varieties," Journal of Agricultural and Food Chemistry, vol. 45, no. 8, pp. 3027-3032, 1997.

[19] V. Ferreira, R. López, and J. F. Cacho, "Quantitative determination of the odorants of young red wines from different grape varieties," Journal of the Science of Food and Agriculture, vol. 80, no. 11, pp. 1659-1667, 2000.

[20] R. A. Peinado, J. Moreno, J. E. Bueno, J. A. Moreno, and J. C. Mauricio, "Comparative study of aromatic compounds in two young white wines subjected to pre-fermentative cryomaceration," Food Chemistry, vol. 84, no. 4, pp. 585-590, 2004.

[21] C. Song, L. Zuo, P. Shi et al., "Aroma characterization of Chinese Hutai- 8 wines: Comparing with Merlot and Cabernet Sauvignon wines," Scientia Horticulturae, vol. 194, pp. 237-245, 2015.

[22] J. Cai, B.-Q. Zhu, Y.-H. Wang et al., "Influence of prefermentation cold maceration treatment on aroma compounds of Cabernet Sauvignon wines fermented in different industrial scale fermenters," Food Chemistry, vol. 154, pp. 217-229, 2014.

[23] E. Yilmaz, "The chemistry of fresh tomato flavor," Turkish Journal of Agriculture and Forestry, vol. 25, no. 3, pp. 149-155, 2001.

[24] B. Pineau, J.-C. Barbe, C. Van Leeuwen, and D. Dubourdieu, "Which impact for $\beta$-damascenone on red wines aroma?" Journal of Agricultural and Food Chemistry, vol. 55, no. 10, pp. 4103-4108, 2007.

[25] C.-T. Peng, Y. Wen, Y.-S. Tao, and Y.-Y. Lan, "Modulating the formation of Meili wine aroma by prefermentative freezing process," Journal of Agricultural and Food Chemistry, vol. 61, no. 7, pp. 1542-1553, 2013.

[26] B. Jiang, Z. Xi, M. Luo, and Z. Zhang, "Comparison on aroma compounds in Cabernet Sauvignon and Merlot wines from 
four wine grape-growing regions in China," Food Research International, vol. 51, no. 2, pp. 482-489, 2013.

[27] A. J. Rodrigues, T. Raimbourg, R. Gonzalez, and P. Morales, "Environmental factors influencing the efficacy of different yeast strains for alcohol level reduction in wine by respiration," LWT-Food Science and Technology, vol. 65, pp. 1038-1043, 2016.

[28] S. Y. Sun, H. S. Gong, X. M. Jiang, and Y. P. Zhao, "Selected nonSaccharomyces wine yeasts in controlled multistarter fermentations with Saccharomyces cerevisiae on alcoholic fermentation behaviour and wine aroma of cherry wines," Food Microbiology, vol. 44, pp. 15-23, 2014.

[29] J. M. González-Sáiz, I. Esteban-Díez, S. Rodríguez-Tecedor, N. Pérez-Del-Notario, I. Arenzana-Rámila, and C. Pizarro, "Modulation of the phenolic composition and colour of red wines subjected to accelerated ageing by controlling process variables," Food Chemistry, vol. 165, pp. 271-281, 2014.

[30] Y. Tao, H. Li, H. Wang, and L. Zhang, "Volatile compounds of young Cabernet Sauvignon red wine from Changli County (China)," Journal of Food Composition and Analysis, vol. 21, no. 8, pp. 689-694, 2008.

[31] I. Lukić, S. Radeka, N. Grozaj, M. Staver, and D. Peršurić, "Changes in physico-chemical and volatile aroma compound composition of Gewürztraminer wine as a result of late and ice harvest," Food Chemistry, vol. 196, pp. 1048-1057, 2016.

[32] J. M. Gambetta, S. E. P. Bastian, D. Cozzolino, and D. W. Jeffery, "Factors influencing the aroma composition of chardonnay wines," Journal of Agricultural and Food Chemistry, vol. 62, no. 28, pp. 6512-6534, 2014.

[33] J. J. Mateo, M. Jiménez, A. Pastor, and T. Huerta, "Yeast starter cultures affecting wine fermentation and volatiles," Food Research International, vol. 34, no. 4, pp. 307-314, 2001.

[34] D. Chen, Z. Y. Yap, and S.-Q. Liu, "Evaluation of the performance of Torulaspora delbrueckii, Williopsis saturnus, and Kluyveromyces lactis in lychee wine fermentation," International Journal of Food Microbiology, vol. 206, pp. 45-50, 2015.

[35] K. M. Williams, P. Liu, and J. C. Fay, "Evolution of ecological dominance of yeast species in high-sugar environments," Evolution, vol. 69, no. 8, pp. 2079-2093, 2015.

[36] L. Conterno, E. Aprea, P. Franceschi, R. Viola, and U. Vrhovsek, "Overview of Dekkera bruxellensis behaviour in an ethanolrich environment using untargeted and targeted metabolomic approaches," Food Research International, vol. 51, no. 2, pp. 670678, 2013.

[37] S. M. G. Saerens, F. Delvaux, K. J. Verstrepen, P. Van Dijck, J. M. Thevelein, and F. R. Delvaux, "Parameters affecting ethyl ester production by Saccharomyces cerevisiae during fermentation," Applied and Environmental Microbiology, vol. 74, no. 2, pp. 454461, 2008.

[38] C. P. Panceri, J. S. De Gois, D. L. G. Borges, and M. T. BordignonLuiz, "Effect of grape dehydration under controlled conditions on chemical composition and sensory characteristics of Cabernet Sauvignon and Merlot wines," LWT-Food Science and Technology, vol. 63, no. 1, pp. 228-235, 2015.

[39] M. Berenguer, S. Vegara, E. Barrajón, D. Saura, M. Valero, and N. Martí, "Physicochemical characterization of pomegranate wines fermented with three different Saccharomyces cerevisiaeyeast strains," Food Chemistry, vol. 190, pp. 848-855, 2016.

[40] M. Figueiredo-González, B. Cancho-Grande, J. Simal-Gándara, N. Teixeira, N. Mateus, and V. De Freitas, "The phenolic chemistry and spectrochemistry of red sweet wine-making and oak-aging," Food Chemistry, vol. 152, pp. 522-530, 2014.
[41] M. E. Alañón, R. Schumacher, L. Castro-Vázquez, M. C. DíazMaroto, I. Hermosín-Gutiérrez, and M. S. Pérez-Coello, "Enological potential of chestnut wood for aging Tempranillo wines Part II: Phenolic compounds and chromatic characteristics," Food Research International, vol. 51, no. 2, pp. 536-543, 2013.

[42] S. Pérez-Magariño and M. L. González-San José, "Evolution of Flavanols, Anthocyanins, and Their Derivatives during the Aging of Red Wines Elaborated from Grapes Harvested at Different Stages of Ripening," Journal of Agricultural and Food Chemistry, vol. 52, no. 5, pp. 1181-1189, 2004.

[43] K. M. Sumby, P. R. Grbin, and V. Jiranek, "Microbial modulation of aromatic esters in wine: Current knowledge and future prospects," Food Chemistry, vol. 121, no. 1, pp. 1-16, 2010.

[44] J. E. Welke, M. Zanus, M. Lazzarotto, and C. Alcaraz Zini, "Quantitative analysis of headspace volatile compounds using comprehensive two-dimensional gas chromatography and their contribution to the aroma of Chardonnay wine," Food Research International, vol. 59, pp. 85-99, 2014.

[45] M. Zhang, Q. Pan, G. Yan, and C. Duan, "Using headspace solid phase micro-extraction for analysis of aromatic compounds during alcoholic fermentation of red wine," Food Chemistry, vol. 125, no. 2, pp. 743-749, 2011.

[46] E. Gómez García-Carpintero, M. A. Gómez Gallego, E. Sánchez-Palomo, and M. A. González Viñas, "Impact of alternative technique to ageing using oak chips in alcoholic or in malolactic fermentation on volatile and sensory composition of red wines," Food Chemistry, vol. 134, no. 2, pp. 851-863, 2012. 

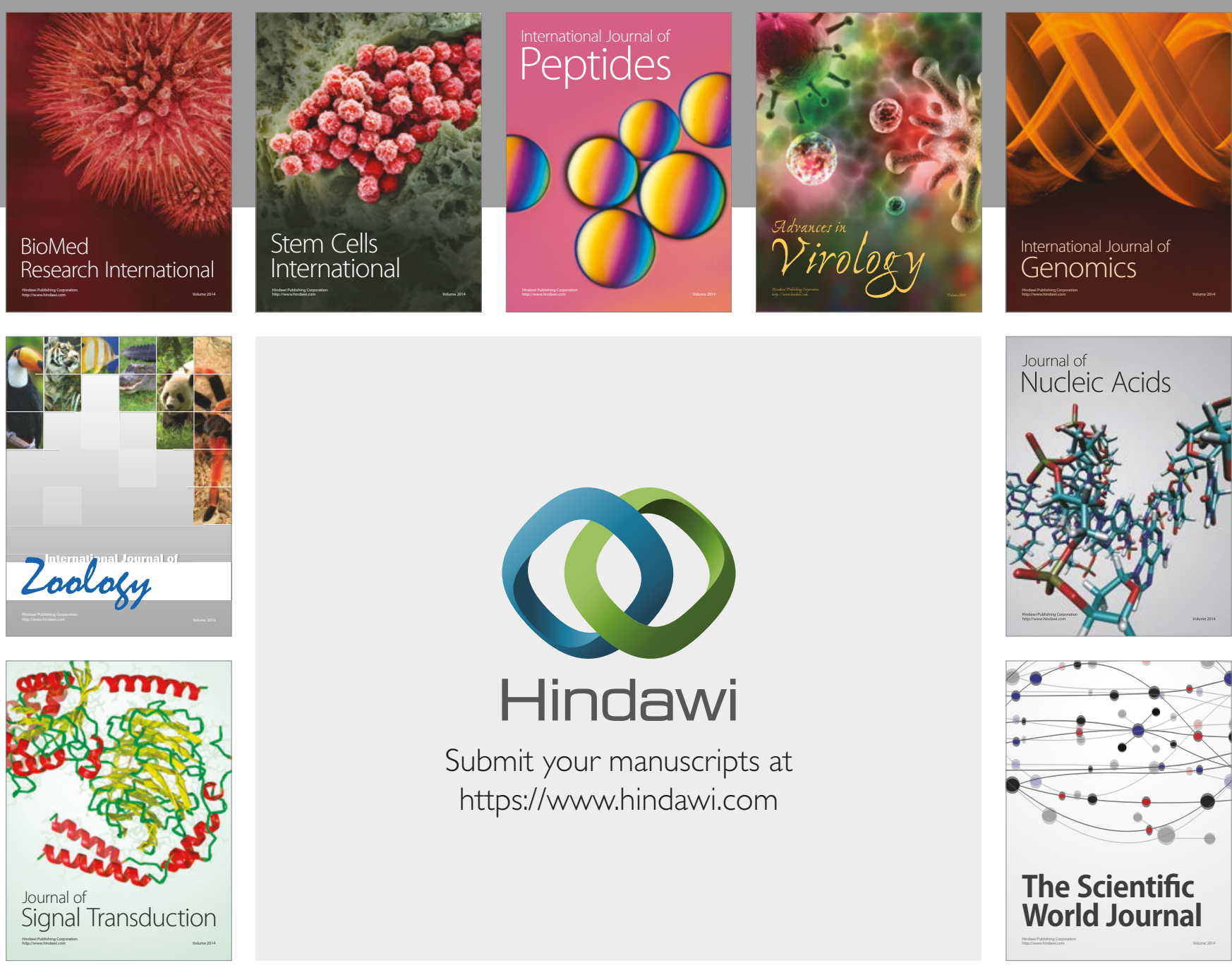

Submit your manuscripts at

https://www.hindawi.com
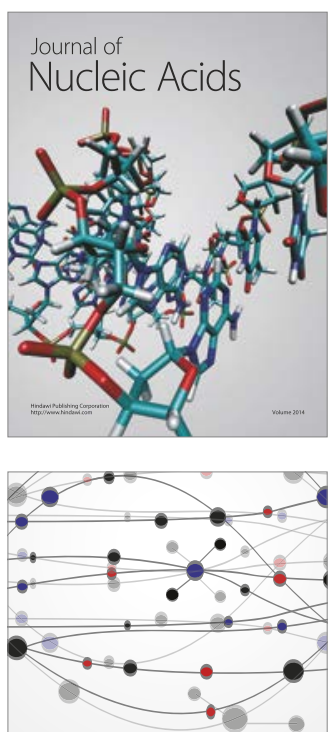

The Scientific World Journal

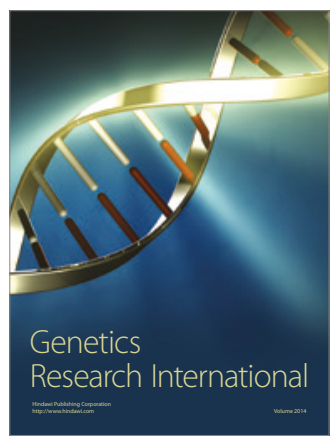

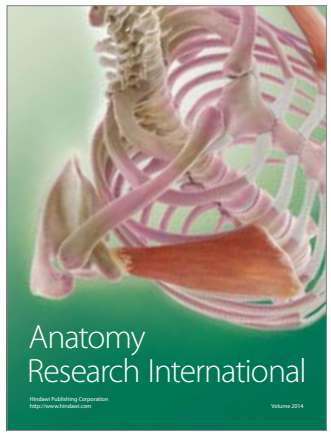

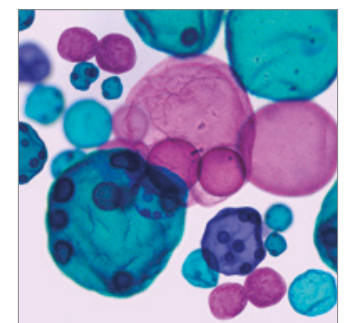

International Journal of Microbiology
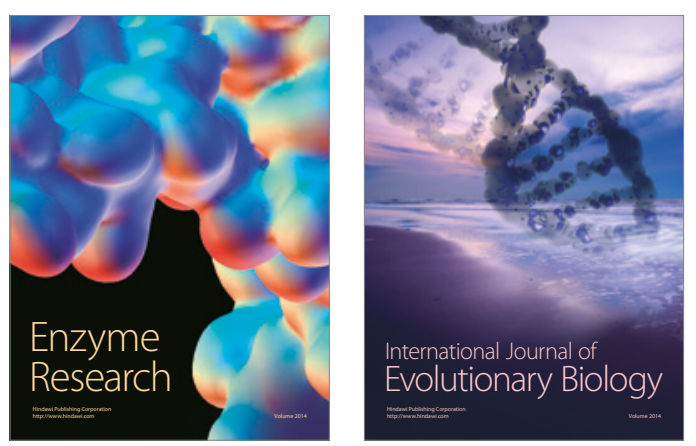
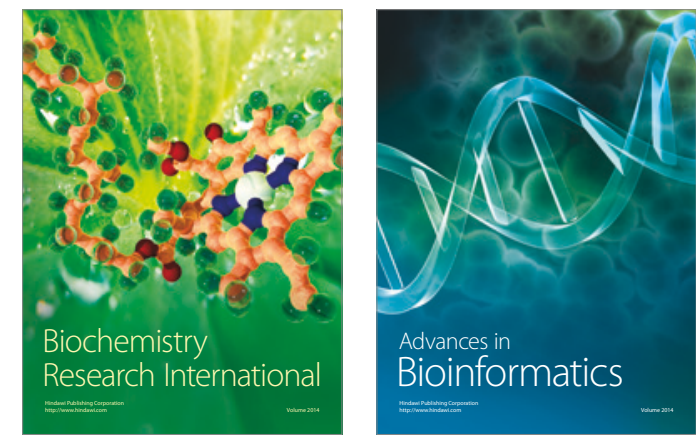

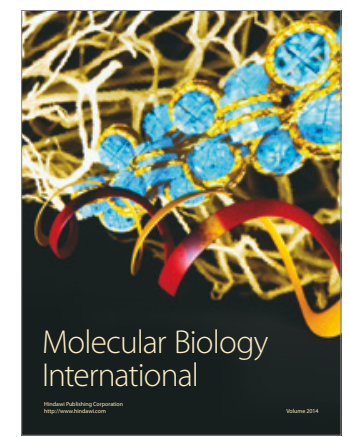

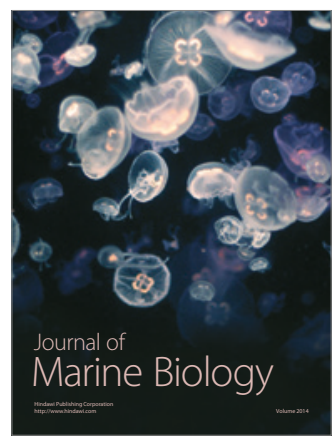

